\title{
The effect of lung biopsy on lung function in diffuse lung disease
}

\author{
Z. Daniil*, F.C. Gilchrist*, S.J. Marciniak*, P. Pantelidis*, P. Goldstraw**, \\ U. Pastorino**, R.M. du Bois*
}

The effect of lung biopsy on lung function in diffuse lung disease. Z. Daniil, F.C. Gilchrist, S.J. Marciniak, P. Pantelidis, P. Goldstraw, U. Pastorino, R.M. du Bois. (C)ER Journals Ltd 2000.

ABSTRACT: The aim of this study was to investigate the effect on lung function of lung biopsy used in the diagnosis of diffuse lung disease carried out by an open procedure or by video-assisted thoracoscopy.

One hundred and sixteen patients with diffuse lung disease who attended the Royal Brompton Hospital were studied retrospectively. Thirty five patients underwent open lung biopsy, and 33 video-assisted thoracoscopic biopsy and 48 had their diagnosis made without biopsy. All patients underwent lung function tests before and after surgery, or at an interval of 3-6 months in those who did not undergo biopsy.

No significant differences were found in changes in lung function between those who had and had not undergone biopsy, and the proportions of patients whose lung function improved or deteriorated were similar. Lung biopsy by an open procedure or by video-assisted thoracoscopy did not differ in its effects on lung function. The results for older patients, those with severe disease and those with fibrosing alveolitis were the same as for the whole group.

Open lung biopsy for the diagnosis of diffuse lung disease does not deleteriously affect lung function whether carried out by an open or a minimally invasive procedure.

Eur Respir J 2000; 16: 67-73.
*Interstitial Lung Disease Unit, Dept of Occupational and Environmental Medicine, and ${ }^{* *}$ Dept of Surgery, Royal Brompton Hospital NHS Trust, London, UK.

Correspondence: RM du Bois, Royal Brompton Hospital, Sydney Street, London SW3 6NP, UK. Fax: 442073518336

Keywords: Diffuse lung disease interstitial lung disease

lung biopsy

open lung biopsy

pulmonary function

video-assisted thoracoscopic biopsy

Received: January 201999

Accepted after revision April 62000
Diffuse lung disease (DLD) remains a significant diagnostic and clinical challenge despite advances in the understanding of its pathology. The mainstay of treatment is corticosteroids combined with other immunosuppressive agents whose long-term administration can have significant side-effects. A definitive diagnosis and an accurate assessment of prognosis are vital before embarking upon a treatment regimen.

The radiological diagnosis of DLD has improved since the introduction of high-resolution computed tomography (HRCT). HRCT appearances have been shown to predict the histological findings at open lung biopsy and to be of prognostic value [1-4]. However, HRCT does not always allow conclusive differentiation of one form of DLD from another [5] and lung biopsy remains essential whenever there is any doubt regarding diagnosis or prognosis.

Video-assisted thoracoscopic lung biopsy (VATS) is a minimally invasive technique that allows operative access to the pleural cavity without thoracotomy $[6,7]$. It provides tissue of similar quality and quantity to open lung biopsy (OLB) but, in some reports, has fewer postoperative complications. Pleural drainage and length of hospital stay are both reduced compared with OLB $[8,9]$.

The majority of previous studies have focused on the short-term postoperative morbidity associated with lung biopsy procedures. Longer-term effects such as those on lung function have not been studied. It has been suggested that lung biopsy may cause a deterioration in lung function and this may partly explain the reluctance of many phy- sicians in the UK to include lung biopsy in the evaluative process [10]. The goals of the present study were to examine the effects of lung biopsy on lung function and to compare the consequences of OLB and VATS. As a control, lung function changes were investigated over a similar period of time in a group of patients with comparable lung function impairment who did not undergo biopsy.

\section{Methods}

\section{Subject selection}

Table 1 shows the full demographic details of the study populations.

\section{Video-assisted thoracoscopic lung biopsy group}

The VATS group consisted of 33 adults, median age 53 yrs (range 23-74 yrs), 11 male and 22 female, who presented at the Interstitial Lung Disease Unit of the Royal Brompton Hospital between April 1993 and May 1997 and underwent VATS for the diagnosis of DLD. Subjects were identified from hospital data and review of the medical records of all patients seen in the unit who had undergone VATS in the Department of Surgery during the study period. All patients included in the study had performed 
Table 1. - Demographic characteristics and indices of lung function at presentation for all patients

\begin{tabular}{lccc}
\hline & $\begin{array}{c}\text { VATS } \\
\text { group }\end{array}$ & $\begin{array}{c}\text { OLB } \\
\text { group }\end{array}$ & $\begin{array}{c}\text { Control } \\
\text { group }\end{array}$ \\
\hline Subjects n & 33 & 35 & 48 \\
Age yrs & $53(23-74)$ & $50(27-85)$ & $50(24-73)$ \\
Sex male/female & $11 / 22$ & $18 / 17$ & $13 / 35$ \\
Smoking ever/NS & $12 / 21$ & $13 / 22$ & $24 / 24$ \\
Diagnosis: n & & & \\
$\quad$ FASSc & 15 & 12 & 31 \\
CFA & 7 & 15 & 9 \\
Sarcoidosis & 3 & 5 & 4 \\
EAA & 5 & 2 & 3 \\
COP & 1 & 0 & 0 \\
Churg-Strauss & 2 & 0 & 1 \\
Polymyositis FA & 0 & 1 & 0 \\
FVC \% pred & $77.0 \pm 3.3$ & $74 \pm 3.8$ & $78.9 \pm 3.5$ \\
DL,CO \% pred & $51.9 \pm 2.8$ & $46 \pm 2$ & $49.7 \pm 2.5$ \\
Treatment (at time of & $14(42.4)$ & $22(63)$ & $18(37.5)$ \\
second PFTs) n (\%) & & & \\
\hline
\end{tabular}

Data are presented as absolute numbers, median (range) or mean \pm SEM. VATS: video-assisted thoracoscopic lung biopsy; OLB: open lung biopsy; NS: never-smoker; FASSc: fibrosing alveolitis associated with systemic sclerosis; CFA: cryptogenic fibrosing alveolitis; EAA: extrinsic allergic alveolitis; COP: cryptogenic organizing pneumonia; polymyositis FA: polymyositis associated with fibrosing alveolitis; FVC: forced vital capacity; $D$ L,CO: diffusing capacity of the lung for carbon monoxide; PFT: pulmonary function test; \% pred: percentage of the predicted value.

pulmonary function tests (PFTs) 1-2 months before and 24 months after VATS. All patients had a definitive diagnosis made on VATS.

\section{Open lung biopsy group}

The OLB group consisted of 35 patients, 18 males and 17 females, median age 50 yrs (range 27-85 yrs), identified from hospital and medical records who had undergone OLB for the diagnosis of DLD between March 1986 and October 1990. The group was comparable with the VATS group with regard to age, sex, smoking habits and lung function. All patients had performed PFTs $\geq 1-2$ months before and 2-4 months after the OLB.

\section{Control group}

The control group consisted of patients presenting to the unit between April 1993 and May 1997 who did not undergo VATS. The group was made up of 48 patients, median age $50 \mathrm{yrs}$, (range 24-73 yrs), of whom 13 were male and 35 female. They were comparable with the other two groups with regard to age, sex, diagnosis and disease severity. All patients had performed two full PFTs 3-6 months apart but had not undergone lung biopsy between the two measurements. Diagnoses are shown in table 1. Subjects with fibrosing alveolitis associated with systemic sclerosis (FASSc) were included provided that: 1) the diagnostic criteria of the American Rheumatism Association [11] were fulfilled; 2) the reason for referral to the unit was to evaluate suspected pulmonary complications of systemic sclerosis; and 3) there was evidence of pulmonary fibrosis on clinical and radiological (HRCT) grounds. The diagnosis of cryptogenic fibrosing alveolitis (CFA) was made on the basis of clinical and radiological criteria (HRCT). All patients with sarcoidosis yielded a positive Kveim biopsy and the patient with Churg-Strauss syndrome showed compatible clinical features and skin biopsy results that confirmed vasculitis. Patients with extrinsic allergic alveolitis (EAA) had histories of exposure and clinical findings suggesting EAA, with compatible HRCT and bronchoalveolar lavage findings. In the groups undergoing biopsy, the diagnosis was confirmed by histopathology.

\section{Treatment}

At the time of the second lung function measurement, 14 $(42.4 \%)$ patients in the VATS group, $18(37.5 \%)$ in the control group, and $22(62.9 \%)$ in the OLB group were receiving therapy for their disease. Five patients in the VATS group, five in the control group and 15 in the OLB group were treated with prednisolone alone (daily dose range $10-60 \mathrm{mg}$ ). Nine patients in the VATS group, 12 in the control group and seven in the OLB group were treated with prednisolone in combination with azathioprine (100$150 \mathrm{mg}$ daily) or with cyclophosphamide (50-125 mg daily). One patient in the control group was treated with interferon- $\alpha$.

\section{Pulmonary function tests}

Pulmonary function tests, including measurement of forced expiratory volume in one second (FEV1), forced vital capacity (FVC), total lung capacity (TLC), carbon monoxide diffusing capacity of the lung $(D \mathrm{~L}, \mathrm{CO})$ and carbon monoxide diffusing capacity adjusted for alveolar volume $(\mathrm{KCO})$, were performed 1-2 months before and 24 months after the biopsy procedure in the VATS and OLB groups. In the control group, the time interval between the PFTs was 3-6 months.

Throughout the study period, an Ohio water-seal spirometer (Ohio Instruments, Atlanta, GA, USA) was used to measure lung volumes. TLC was measured in a wholebody plethysmograph (Fenyves and Gut, Basle, Switzerland). Measures of gas transfer ( $D \mathrm{~L}, \mathrm{CO}$ and $K \mathrm{CO})$ were assessed by the single-breath technique using a PK Morgan respirometer (Morgan Medical Limited, Rainham, Gillingham, UK). Lung function measurements were expressed as percentages of values predicted from the subjects' age, sex, height and ethnic origin [12]. Criteria used to define significant change were: deterioration: a decline of $>15 \%$ from baseline values; stability: no change or a change of $\pm 15 \%$ from baseline values; and improvement: a rise of $>15 \%$ from baseline values, as used in previous studies $[13,14]$.

\section{Video-assisted thoracoscopic lung biopsy}

Video-assisted thoracoscopy and wedge resection were performed under general anaesthesia using a linear endoscopic stapler at two different sites depending on disease distribution. 


\section{Open lung biopsy}

Open lung biopsy was performed using a modified version of the technique first described by KLASSEN et al. [15]. The most common approach used was a limited anterolateral thoracotomy via a 4-10 cm submammary incision, which allowed access to segments of all three lobes of the right lung.

If there was clear radiological evidence of bilateral disease and no obvious clinical indication for left lung biopsy, the right lung was chosen for both the VATS and open biopsy procedures, Computed tomography was a key determinant of site selection for biopsy.

\section{Statistical methods}

Subgroup comparisons were made using the MannWhitney U-test or a two-tailed paired t-test for normally distributed variables. Lung function indices were normally distributed and comparisons between subgroups in table 1 showed no difference using the t-test.

Comparisons of differences between the first and second pulmonary function measurements were made using the Wilcoxon matched-pairs test to compare differences between absolute (not percentage) measurements.

Comparisons of the frequency of improvement or decline in PFT results between groups and subgroups were made using the Chi-squared test or the Chi-squared test with Yates' correction when patient numbers were small. A p-value of $<0.05$ was considered significant.

\section{Results}

\section{Subject characteristics}

One hundred and sixteen subjects were studied. Thirtythree underwent VATS for the diagnosis of DLD and 35 OLB and 48 (control group) had their diagnosis made without biopsy. There were no significant differences in age or smoking habits between the three groups. FVC and $D$ L,CO before biopsy in the VATS and OLB groups, and at the first measurement in the control group, were similar $(\mathrm{p}>0.05)$ (table 1).
Changes in lung function test results observed in the three groups

No significant differences were observed in lung function test results (FEV1, FVC, TLC, DL, CO and KCO) before and after the operative procedure in either the VATS group or the OLB group ( $\mathrm{p}>0.05)$. The changes seen in the control group between the first and second measurement were similar to those seen in patients who had undergone surgery (table 2).

\section{Individual data}

When group data were considered, neither procedure produced significant changes in PFT results. However, when individual cases were analysed, several patients in each group were found to show significant decreases in lung function.

Three $(9.1 \%)$ patients in the VATS group and three $(8.6 \%)$ patients in the OLB group demonstrated a significant decline of $>15 \%$ in FVC and/or DL,CO after biopsy. The characteristics of these patients are summarized in table 3 . The distribution of their lung function values was typical of the population as a whole. Five of the six patients suffered from fibrosing alveolitis, either alone (CFA) or in association with systemic sclerosis (FASSc).

In order to determine whether the fall in PFT results in this group was due to disease progression rather than the biopsy procedure, they were compared with those in the control group who showed a significant deterioration in lung function. This group did not differ significantly from the biopsy population in any index, including lung function impairment and the proportion on treatment at the time of the second lung function measurement (one of three in the VATS group, two of three in the OLB group and six of nine in the control group). Nine $(18.7 \%)$ patients in the control group deteriorated compared with $9.1 \%$ in the VATS group and $8.6 \%$ in the OLB group. These proportions were not significantly different $(\mathrm{p}>0.05)$.

Five $(15.2 \%)$ patients in the VATS group showed an improvement in FVC and/or DL,CO after VATS, whereas $25(75.8 \%)$ patients were stable. Five $(10.4 \%)$ patients in

Table 2. - Lung function data before and after video-assisted thoracoscopic lung biopsy (VATS) or open lung biopsy (OLB) and at the first and second measurement in the control group

\begin{tabular}{|c|c|c|c|c|c|c|}
\hline & \multicolumn{2}{|c|}{ VATS group } & \multicolumn{2}{|c|}{ OLB group } & \multicolumn{2}{|c|}{ Control group } \\
\hline & Before & After & Before & After & Before & After \\
\hline FEV $1 \%$ pred & $75.0 \pm 2.7$ & $74.0 \pm 2.7$ & $71.1 \pm 3.6$ & $73.7 \pm 3.0$ & $79.1 \pm 3.2$ & $76.3 \pm 3.4$ \\
\hline $\mathrm{L}$ & $2.13 \pm 0.90$ & $2.12 \pm 0.90$ & $2.19 \pm 0.11$ & $2.20 \pm 0.11$ & $2.16 \pm 0.10$ & $2.12 \pm 0.10$ \\
\hline FVC \% pred & $77.0 \pm 3.3$ & $76.3 \pm 3.5$ & $74.4 \pm 3.8$ & $77.4 \pm 3.3$ & $78.9 \pm 3.5$ & $76.7 \pm 3.7$ \\
\hline $\mathrm{L}$ & $2.60 \pm 1.24$ & $2.61 \pm 1.27$ & $2.78 \pm 0.15$ & $2.81 \pm 0.15$ & $2.60 \pm 0.13$ & $2.58 \pm 0.14$ \\
\hline TLC \% pred & $75.4 \pm 3.1$ & $75.8 \pm 2.8$ & $72.3 \pm 2.6$ & $72.2 \pm 2.6$ & $74.9 \pm 2.7$ & $73.0 \pm 2.8$ \\
\hline $\mathrm{L}$ & $4.08 \pm 1.60$ & $4.1 \pm 1.70$ & $4.21 \pm 0.21$ & $4.18 \pm 0.2$ & $4.05 \pm 0.19$ & $3.93 \pm 0.18$ \\
\hline$D \mathrm{~L}, \mathrm{CO} \%$ pred & $51.9 \pm 2.8$ & $51.7 \pm 2.9$ & $46.4 \pm 2.0$ & $48.7 \pm 2.1$ & $49.7 \pm 2.5$ & $50.4 \pm 2.8$ \\
\hline $\mathrm{mmol} \cdot \mathrm{min}^{-1} \cdot \mathrm{kPa}^{-1}$ & $4.45 \pm 0.20$ & $4.50 \pm 0.20$ & $4.19 \pm 0.19$ & $4.38 \pm 0.19$ & $4.18 \pm 0.21$ & $4.21 \pm 0.23$ \\
\hline KCO \% pred & $77.2 \pm 2.7$ & $79.5 \pm 3.1$ & $77.7 \pm 3.2$ & $81.5 \pm 3.5$ & $78.8 \pm 2.4$ & $78.9 \pm 2.5$ \\
\hline $\mathrm{mmol} \cdot \mathrm{min}^{-1} \cdot \mathrm{kPa}^{-1}$ & $1.28 \pm 0.05$ & $1.3 \pm 0.05$ & $1.29 \pm 0.06$ & $1.35 \pm 0.07$ & $1.38 \pm 0.08$ & $1.39 \pm 0.08$ \\
\hline
\end{tabular}

Data are presented as mean \pm SEM. FEV1: forced expiratory volume in one second; FVC: forced vital capacity; TLC: total lung capacity; $D$ L,CO: diffusing capacity of the lung for carbon monoxide; $K C O$ : carbon monoxide diffusing capacity adjusted for alveolar volume; $\%$ pred: percentage of the predicted value. 
Table 3. - Characteristics of all patients who showed a deterioration in lung function

\begin{tabular}{|c|c|c|c|c|c|c|c|c|c|}
\hline $\begin{array}{l}\text { Patient } \\
\text { No. }\end{array}$ & $\begin{array}{l}\text { Age } \\
\text { Yrs }\end{array}$ & Sex & Smoking & Diagnosis & $\begin{array}{l}\text { FVC* } \\
\% \text { pred }\end{array}$ & $\begin{array}{l}D \mathrm{~L}, \mathrm{CO} * \\
\% \text { pred }\end{array}$ & Treatment $^{+}$ & $\begin{array}{l}\text { FVC loss } \\
\text { \% baseline }\end{array}$ & $\begin{array}{l}D \mathrm{~L}, \mathrm{CO} \text { loss } \\
\text { \% baseline }\end{array}$ \\
\hline \multicolumn{10}{|c|}{ VATS group } \\
\hline 1 & 47 & M & $\mathrm{S}$ & FASSc & 64 & 24 & $\mathrm{~N}$ & 11.2 & 25.5 \\
\hline 2 & 58 & $\mathrm{~F}$ & NS & Sarcoidosis & 56 & 71 & $\mathrm{Y}$ & 15.3 & 6.4 \\
\hline 3 & 27 & $\mathrm{~F}$ & NS & FASSc & 84 & 62 & $\mathrm{~N}$ & 24.5 & 37.0 \\
\hline \multicolumn{10}{|c|}{ OLB group } \\
\hline 1 & 64 & M & NS & CFA & 72 & 49 & Y & 16.7 & 20.5 \\
\hline 2 & 49 & $\mathrm{M}$ & NS & CFA & 41 & 37 & $\mathrm{~N}$ & 16.6 & 9.2 \\
\hline 3 & 54 & M & NS & CFA & 106 & 53 & $\mathrm{Y}$ & 18.6 & 20.1 \\
\hline \multicolumn{10}{|c|}{ Control group } \\
\hline 1 & 51 & $\mathrm{~F}$ & EX & FASSc & 59 & 34 & $\mathrm{Y}$ & 35.4 & 26.4 \\
\hline 2 & 48 & $\mathrm{~F}$ & EX & FASSc & 76 & 52 & $\mathrm{Y}$ & 22.5 & 9.1 \\
\hline 3 & 52 & M & NS & FASSc & 63 & 51 & $\mathrm{~N}$ & 17.2 & 7.6 \\
\hline 4 & 41 & M & NS & FASSc & 26 & 13 & $\mathrm{Y}$ & 22.8 & 10.4 \\
\hline 5 & 60 & $\mathrm{~F}$ & NS & FASSc & 76 & 55 & Y & 13.7 & 36.0 \\
\hline 6 & 73 & $\mathrm{~F}$ & EX & FASSc & 96 & 72 & $\mathrm{~N}$ & 2.3 & 15.5 \\
\hline 7 & 61 & $\mathrm{~F}$ & EX & EAA & 71 & 33 & $\mathrm{Y}$ & 17.4 & 7.5 \\
\hline 8 & 64 & $\mathrm{~F}$ & EX & EAA & 57 & 45 & $\mathrm{~N}$ & 0.0 & 17.3 \\
\hline 9 & 35 & M & $\mathrm{S}$ & FASSc & 99 & 50 & $\mathrm{Y}$ & 2.3 & 20.3 \\
\hline
\end{tabular}

*: on presentation; ${ }^{+}$: at time of second pulmonary function tests; ${ }^{*}$ : change in absolute numbers as percentage of baseline value. FVC: forced vital capacity; DL,CO: diffusing capacity of the lung for carbon monoxide; VATS: video-assisted thoracoscopic lung biopsy; OLB: open lung biopsy; M: male; F: female; S: smoker; NS: nonsmoker; Ex: exsmoker; FASSc: fibrosing alveolitis associated with symptomatic sclerosis; CFA: cryptogenic fibrosing alveolitis; EAA: extrinsic allergic alveolitis; Y: yes; N: no.

the control group showed an improvement in FVC and/or $D$ L,CO, whereas $34(70.8 \%)$ were stable. In the OLB group eight $(22.9 \%)$ patients improved and $24(68.6 \%)$ remained stable. Table 4 summarizes the characteristics of all patients who demonstrated an increase in FVC and/or $D$ L,CO. Those who improved following VATS differed from those who improved after OLB or, in the case of the control group, at the second lung function measurement in distribution of diagnoses. In the VATS group, the majority of patients (four of five) had disease likely to improve with therapy. In the OLB group, one patient was diagnosed with EAA and one with sarcoidosis, and the remaining six had fibrosing alveolitis. In the control group, all patients who improved had fibrosing alveolitis. Again, these differences were nonsignificant when this small subgroup of patients was considered.

Table 4. - Characteristics of all patients who showed an improvement in lung function

\begin{tabular}{|c|c|c|c|c|c|c|c|c|c|}
\hline $\begin{array}{l}\text { Patient } \\
\text { No. }\end{array}$ & $\begin{array}{l}\text { Age } \\
\text { Yrs }\end{array}$ & Sex & Smoking & Diagnosis & $\begin{array}{l}\text { FVC* } \\
\% \text { pred }\end{array}$ & $\begin{array}{l}D \mathrm{~L}, \mathrm{CO}^{*} \\
\% \text { pred }\end{array}$ & Treatment $^{+}$ & $\begin{array}{c}\Delta \mathrm{FVC} \\
\% \text { baseline }^{\#}\end{array}$ & $\begin{array}{c}\Delta D \mathrm{~L}, \mathrm{CO} \\
\% \text { baseline }^{\#}\end{array}$ \\
\hline \multicolumn{10}{|c|}{ VATS group } \\
\hline 1 & 53 & $\mathrm{M}$ & EX & FASSc & 88 & 53 & Y & 8.1 & 24.2 \\
\hline 2 & 36 & $\mathrm{~F}$ & NS & COP & 73 & 34 & $\mathrm{Y}$ & 30.0 & 37.0 \\
\hline 3 & 40 & $\mathrm{~F}$ & NS & Churg-Strauss & 67 & 73 & Y & 15.9 & 9.1 \\
\hline 4 & 53 & $\mathrm{~F}$ & NS & Churg-Strauss & 108 & 60 & Y & 3.9 & 21.0 \\
\hline 5 & 56 & $\mathrm{~F}$ & EX & EAA & 80 & 52 & $\mathrm{~N}$ & 23.0 & 29.0 \\
\hline \multicolumn{10}{|c|}{ OLB group } \\
\hline 1 & 34 & $\mathrm{M}$ & $\mathrm{S}$ & CFA & 54 & 47 & $\mathrm{Y}$ & 35.1 & 18.9 \\
\hline 2 & 53 & $\mathrm{~F}$ & NS & FASSc & 55 & 28 & Y & 8.3 & 15.8 \\
\hline 3 & 45 & $\mathrm{~F}$ & NS & CFA & 51 & 52 & $\mathrm{Y}$ & 32.0 & 43.3 \\
\hline 4 & 48 & $\mathrm{M}$ & NS & CFA & 35 & 22 & $\mathrm{Y}$ & 18.0 & 45.0 \\
\hline 5 & 48 & $\mathrm{~F}$ & NS & EAA & 66 & 31 & $\mathrm{~N}$ & 16.4 & 22.0 \\
\hline 6 & 40 & $\mathrm{~F}$ & NS & FASSc & 66 & 37 & Y & 0.0 & 34.6 \\
\hline 7 & 49 & $\mathrm{~F}$ & NS & Sarcoidosis & 62 & 48 & Y & 25.0 & 15.6 \\
\hline 8 & 85 & $\mathrm{~F}$ & NS & CFA & 65 & 39 & $\mathrm{Y}$ & 49.0 & 33.5 \\
\hline \multicolumn{10}{|c|}{ Control group } \\
\hline 1 & 47 & $\mathrm{~F}$ & EX & FASSc & 71 & 29 & Y & 7.2 & 15.6 \\
\hline 2 & 24 & $\mathrm{~F}$ & NS & FASSc & 63 & 49 & $\mathrm{~N}$ & 17.5 & 12.2 \\
\hline 3 & 47 & $\mathrm{~F}$ & NS & FASSc & 57 & 43 & Y & 6.1 & 44.9 \\
\hline 4 & 46 & $\mathrm{~F}$ & EX & FASSc & 85 & 34 & Y & 1.7 & 17.6 \\
\hline 5 & 70 & M & EX & CFA & 114 & 41 & Y & 9.0 & 17.5 \\
\hline
\end{tabular}

*: on presentation; ${ }^{+}$: at time of second pulmonary function tests; ${ }^{\#}$ : change in absolute numbers as percentage of baseline value. FVC: forced vital capacity; $D$ L,CO: diffusing capacity of the lung for carbon monoxide; $\Delta$ : change in; VATS: video-assisted thoracoscopic lung biopsy; OLB: open lung biopsy; M: male; F: female; Ex: exsmoker; NS: nonsmoker; S: smoker; FASSc: fibrosing alveolitis associated with symptomatic sclerosis; COP: cryptogenic organizing pneumonia; EAA: extrinsic allergic alveolitis; CFA: cryptogenic fibrosing alveolitis; Y: yes; N: no. 
Changes in pulmonary function test results in older patients and patients with severe disease

Patients aged $\geq 60$ yrs and those with an FVC of $<60 \%$ of the predicted value were investigated to determine whether age or severity of disease was a risk factor for a postoperative deterioration. The lung function changes in these subsets mirrored those of the group as a whole for those who had undergone either VATS or OLB and those who had received no operative intervention (table 5).

\section{Changes in pulmonary function test results in patients with fibrosing alveolitis}

In order to investigate whether fibrosing alveolitis is an independent risk factor for a postoperative decline in PFT results, patients with CFA and FASSc were analysed separately. Lung function data for this group of patients are shown in table 6. No significant changes were observed in PFT results in the VATS fibrosing alveolitis, the OLB fibrosing alveolitis or the control fibrosing alveolitis group between the first and second lung function measurements.

Although the changes in lung function for patients with fibrosing alveolitis were not significant when the groups were considered as a whole, there were individual cases in which there was a considerable deterioration in lung function. Two $(9.1 \%)$ patients in the VATS group, seven $(17.5 \%)$ patients in the control group and $3(11.1 \%)$ patients in the OLB group demonstrated a decline of $>15 \%$ in FVC and/or $D$ L,CO.

\section{Effects of treatment}

Because of the possibility that treatment effects may have confounded the data, changes in lung function were explored with regard to whether or not the patient received treatment. In each group, similar numbers of patients who deteriorated or improved were on no treatment at the time of the second lung function measurement.

No significant changes in lung function were found in patients who remained untreated when the second PFT measurements were performed in any of the three groups. Comparison of the frequency of improvement and deterioration with treatment did not show any significant differences in the three groups.

\section{Discussion}

Patients with diffuse (interstitial) lung disease comprise a group in whom lung biopsy may be necessary to establish a diagnosis. However, biopsy is often avoided because of the potential morbidity that is believed to be associated with the procedure. It has commonly been presumed, but never proven, that lung biopsy, involving either thoracoscopy or OLB, produces a deficit in lung function that is significant and irretrievable. This may explain why lung biopsy is utilized so infrequently in the UK. In one series, only $12 \%$ of patients with suspected CFA underwent OLB. Age and poor lung function were the most important factors that led to the decision to avoid this investigation [10].

At present, many patients are treated empirically with steroids and occasionally other immunosuppressive agents. Lung biopsy is often reserved for those in whom empirical therapy has failed or cases in which the patient is desperately ill on the intensive care unit and all other options have been exhausted. At this time, the risks of the procedure are greatly increased due to disease progression and the effects of treatment, particularly corticosteroids, on wound healing.

This present study has demonstrated that lung biopsy (carried out by the VATS or traditional OLB procedure) does not result in a significant decline in lung volumes or gas transfer for carbon monoxide. Furthermore, although some individuals from each biopsy group did suffer postoperative declines of $\geq 15 \%$, it was shown that such deterioration is as common in those who do not undergo biopsy as in those who do. In a subset of patients, significant improvement in PFT results was seen after biopsy. In order to ensure that studying a mixed population of patients did not have a confounding effect on the data, those patients with fibrosing alveolitis, those in the older age group and those with more severe lung function deficit were analysed separately and no differences found from

Table 5. - Changes in lung function indices before and after video-assisted thoracoscopic lung biopsy (VATS) or open lung biopsy (OLB) and at the first and second measurement in the control group for patients aged $>59$ yrs and for those with a forced vital capacity (FVC) of $<60 \%$ of the predicted value (\% pred)

\begin{tabular}{|c|c|c|c|c|c|c|c|c|c|c|}
\hline & \multicolumn{2}{|c|}{ FEV1 \% pred } & \multicolumn{2}{|c|}{ FVC \% pred } & \multicolumn{2}{|c|}{ TLC $\%$ pred } & \multicolumn{2}{|c|}{$D \mathrm{~L}, \mathrm{CO} \%$ pred } & \multicolumn{2}{|c|}{$K \mathrm{CO} \%$ pred } \\
\hline & Before & After & Before & After & Before & After & Before & After & Before & After \\
\hline \multicolumn{11}{|l|}{ VATS group } \\
\hline Age $>59 \mathrm{yrs}^{\#}$ & $78.6 \pm 7.5$ & $78.0 \pm 8.2$ & $78.0 \pm 8.5$ & $78.9 \pm 8.2$ & $72.7 \pm 6.6$ & $73.0 \pm 6.5$ & $49.2 \pm 5.9$ & $50.1 \pm 5.6$ & $72.0 \pm 4.7$ & $72.9 \pm 4.9$ \\
\hline $\mathrm{FVC}<60 \%$ pred $^{+}$ & $55.3 \pm 3.3$ & $55.0 \pm 4.3$ & $51.2 \pm 2.7$ & $52.3 \pm 3.2$ & $58.3 \pm 6.8$ & $62.7 \pm 6.7$ & $40.0 \pm 6.7$ & $41.8 \pm 6.1$ & $75.8 \pm 3.4$ & $80.3 \pm 3.9$ \\
\hline \multicolumn{11}{|l|}{ OLB group } \\
\hline Age $>59$ yrs $^{\#}$ & $73.7 \pm 10.4$ & $79.7 \pm 6.0$ & $89.1 \pm 7.9$ & $92.4 \pm 7.4$ & $73.8 \pm 4.7$ & $74.8 \pm 4.3$ & $47.6 \pm 3.3$ & $50.3 \pm 3.3$ & $76.1 \pm 5.6$ & $78.4 \pm 4.0$ \\
\hline FVC $<60 \%$ pred $^{+}$ & $50.3 \pm 3.5$ & $55.0 \pm 5.3$ & $51.0 \pm 3.3$ & $56.5 \pm 6.4$ & $53.0 \pm 4.4$ & $54.5 \pm 4.7$ & $39.7 \pm 4.6$ & $43.4 \pm 6.4$ & $90.7 \pm 10.2$ & $95.3 \pm 12.0$ \\
\hline \multicolumn{11}{|l|}{ Control group } \\
\hline Age $>59 \mathrm{yrs}^{\S}$ & $84.9 \pm 5.3$ & $81.5 \pm 5.6$ & $89.1 \pm 7.9$ & $92.4 \pm 7.4$ & $73.8 \pm 4.7$ & $74.8 \pm 4.3$ & $47.6 \pm 3.3$ & $50.3 \pm 3.3$ & $76.1 \pm 5.6$ & $78.4 \pm 4.0$ \\
\hline FVC $<60 \%$ pred & $50.9 \pm 3.4$ & $47.0 \pm 3.4$ & $48.5 \pm 3.3$ & $45.0 \pm 3.7$ & $49.5 \pm 2.4$ & $48.0 \pm 3.0$ & $30.8 \pm 3.4$ & $29.9 \pm 4.4$ & $77.9 \pm 6.4$ & $75.2 \pm 6.8$ \\
\hline
\end{tabular}

Data are presented as mean \pm SEM. ${ }^{+}: \mathrm{n}=6 ;{ }^{\#}: \mathrm{n}=9 ;{ }^{\dagger}: \mathrm{n}=10 ;{ }^{\S}: \mathrm{n}=15$. FEV1: forced expiratory volume in one second; TLC: total lung capacity; DL,CO: diffusing capacity of the lung for carbon monoxide; KCO: carbon monoxide diffusing capacity adjusted for alveolar volume. 
Table 6. - Changes in lung function indices in patients with fibrosing alveolitis ${ }^{\star}$

\begin{tabular}{|c|c|c|c|c|c|c|}
\hline & \multicolumn{2}{|c|}{ VATS group } & \multicolumn{2}{|c|}{ OLB group } & \multicolumn{2}{|c|}{ Control group } \\
\hline & Before & After & Before & After & Before & After \\
\hline Subjects n & \multicolumn{2}{|c|}{22} & \multicolumn{2}{|c|}{27} & \multicolumn{2}{|c|}{40} \\
\hline FEV1 $\%$ pred & $77.0 \pm 3.8$ & $75.6 \pm 3.9$ & $72.9 \pm 4.0$ & $75.1 \pm 3.8$ & $76.1 \pm 3.2$ & $75.0 \pm 3.1$ \\
\hline FVC \% pred & $78.2 \pm 4.4$ & $76.8 \pm 4.6$ & $78.8 \pm 3.5$ & $80.1 \pm 4.0$ & $76.2 \pm 3.5$ & $75.4 \pm 3.5$ \\
\hline TLC \% pred & $76.8 \pm 3.7$ & $76.0 \pm 3.4$ & $74.1 \pm 2.6$ & $72.7 \pm 3.1$ & $73.6 \pm 3.0$ & $72.3 \pm 3.0$ \\
\hline$D \mathrm{~L}, \mathrm{CO} \%$ pred & $52.2 \pm 3.2$ & $52.3 \pm 3.2$ & $47.2 \pm 2.2$ & $49.8 \pm 2.8$ & $46.7 \pm 2.4$ & $46.9 \pm 2.5$ \\
\hline KCO \% pred & $75.8 \pm 2.5$ & $81.3 \pm 2.9$ & $76.1 \pm 3.9$ & $81.5 \pm 4.5$ & $76.3 \pm 2.7$ & $75.8 \pm 2.7$ \\
\hline
\end{tabular}

Data are presented as mean \pm SEM. *: cryptogenic fibrosing alveolitis or fibrosing alveolitis associated with systemic sclerosis. VATS: video-assisted thoracoscopic lung biopsy; OLB: open lung biopsy; FEV1: forced expiratory volume in one second; FVC: forced vital capacity; TLC: total lung capacity; DL,CO: diffusing capacity of the lung for carbon monoxide; KCO: carbon monoxide diffusing capacity adjusted for alveolar volume.

the patient population as a whole. Lung function changes in these groups were comparable to those seen in the whole population.

No previous studies have explored the effects of lung biopsy on lung function. It was shown, in this study, that the more recently introduced VATS method is as safe in this respect as the direct-vision more open procedure. A previous study focused on the effect of lung biopsy in the elderly and in those with severely impaired lung function. JAKLITSCH et al. [16] found that neither morbidity nor mortality following VATS is related to age and disease severity. The present study is consistent with this. Patients aged $>60$ yrs and those with an FVC of $<60 \%$ pred were not found to be at a disadvantage compared to the younger or less severe subset following OLB or VATS.

However, among the study population, a significant deterioration in PFT results after biopsy was detected in three patients in the VATS group and three in the OLB group. This deterioration could have been due to the operation or to progression of the underlying disease. Subsets whose lung function declined by similar amounts were found in both control and biopsy populations. This supports the view that a proportion of patients have disease that is rapidly progressive and that lung biopsy per se is not the cause of deteriorating lung function.

A potential criticism of this study is its retrospective nature. However, the complete absence of a significant decline in any single subgroup is definitive and seems to rule out any bias based on the retrospective nature of the study, including decisions that might have affected biopsy or treatment. The decision as to whether or not a biopsy was required was made on clinical grounds rather than random assignment to the biopsy or nonbiopsy groups. Factors that influence the decision as to whether a biopsy is performed are the patient's age, severity of disease and comorbid conditions. The present patient groups were compared and found to be well matched in age and in degree of lung function impairment on presentation. Decisions regarding biopsy were not influenced by rate of disease progression. Thus it seems unlikely that these factors led to bias in selection of patients for biopsy. Another factor that influences the decision regarding biopsy is confidence in diagnosis without an invasive procedure. In those in whom the clinical data give enough information for a secure diagnosis to be reached, biopsy is sometimes not felt to be necessary. This may explain the higher proportion of patients in the control group diagnosed with
FASSc (64.6 versus $45.5 \%$ in the VATS group and $34.3 \%$ in the OLB group). These patients have very characteristic clinical, immunological and radiological features, allowing a diagnosis to be made without recourse to biopsy.

In spite of the limitations due to the retrospective nature of this study, the present results suggest that OLB whether carried out by an open procedure or by the minimally invasive VATS technique, has no significant effect on lung function. The procedures have equally high sensitivity and specificity in the diagnosis of infiltrative lung disease [17] but the morbidity associated with VATS appears to be less. Incisions of limited size are required to visualize most of the pleural and lung surfaces, meaning the lung has to be manipulated less reducing atelectasis, postoperative pain [18] and length of hospital stay [19].

In conclusion, the present study indicates that pulmonary function test results are not adversely affected by lung biopsy performed via either the video-assisted thoracoscopic lung biopsy or open lung biopsy procedure. The significant deterioration in lung function tests following the procedure observed in a few cases was found to reflect progression of the disease process rather than to be due to the intervention. Despite the limitations of retrospective analyses, the present findings suggest that open and videoassisted thoracoscopic lung biopsy are both safe diagnostic tools in the management of diffuse lung disease. Videoassisted thoracoscopic lung biopsy appears to be gaining increasing acceptance worldwide with fewer complications and reduced hospitalization in some reports and seems likely to emerge as the biopsy approach of choice in cases of diffuse lung disease in which noninvasive investigation, most notably high-resolution computed tomography, fails to give a conclusive diagnosis and biopsy is required.

\section{References}

1. Muller NL, Miller RR, Webb WR, Evans KG, Ostrow DN. Fibrosing alveolitis: CT-pathologic correlation. Radiology 1986; 160: 585-588.

2. Nishimura K, Kitaichi M, Izumi T, Nagai S, Knooka M, Itoh H. Usual interstitial pneumonia: histologic correlation with high resolution CT. Radiology 1992; 182: 337342.

3. Muller NL, Staples CA, Miller RR, Vedal S, Thurlbeck WM, Ostrow DN. Disease activity in idiopathic pulmonary fibrosis: CT and pathologic correlation. Radiology 1987; 165: 731-734. 
4. Wells AU, Hansell DM, Rubens MB, Cullinan P, Black $\mathrm{CM}$, du Bois RM. The predictive value of appearances on thin-section computed tomography in fibrosing alveolitis. Am Rev Respir Dis 1993; 148: 1076-1082.

5. Lynch DA, Newell JD, Logan M, King TE, Muller NL. Can CT distinguish hypersensitivity pneumonitis from idiopathic pulmonary fibrosis? Am J Radiol 1995; 165: 807-811.

6. Hazelrigg SR, Nunchuck SK, LoCicero J. Video Assisted Thoracic Surgery Study Group data. Ann Thorac Surg 1993; 56: 1039-1044.

7. Decamp MM, Jaklitsch MT, Mentjer SJ, Harpote DH, Sugarbaker DJ. The safety and versatility of video-thoracoscopy: a prospective analysis of 895 consecutive cases. J Am Coll Surg 1995; 181: 113-120.

8. Carnochan FM, Walker WS, Cameron EW. Efficacy of video assisted thoracoscopic lung biopsy: an historical comparison with open lung biopsy. Thorax 1994; 49: 361-363.

9. Bensard DD, McIntyre RC, Waring BJ, Simons JS. Comparison of video thoracoscopic lung biopsy to open lung biopsy in the diagnosis of interstitial lung disease. Chest 1993; 103: 765-770.

10. Johnston IDA, Prescott RJ, Chalmers JC, Rudd RM. British Thoracic Society study of cryptogenic fibrosing alveolitis: current presentation and initial management. Thorax 1997; 52: 38-44.

11. Subcommittee for Scleroderma Criteria of the American Rheumatism Association Diagnostic and Therapeutic Criteria Committee: Preliminary criteria for the classification of systemic sclerosis (scleroderma). Arthritis Rheum 1980; 23: 581-590.

12. Quanjer PH. Standardised lung function testing. Clin Respir Physiol 1993; 19 (Suppl 5): 1-95.

13. Chinet T, Dusser D, Labrune S, Collignon MA, Chretian J, Huchon GJ. Lung function declines in patients with pulmonary sarcoidosis and increased respiratory epithelial permeability to ${ }^{99 \mathrm{~m}} \mathrm{Tc}$ DTPA. Am Rev Respir Dis 1990; 141: 445-449.

14. Wells AU, Rubens MB, du Bois RM, Hansell DM. Serial $\mathrm{CT}$ in fibrosing alveolitis: prognostic significance of the initial pattern. Am J Radiol 1993; 161: 11591165.

15. Klassen KP, Anylana AJ, Curtis GM. Biopsy of diffuse pulmonary lesions. Arch Surg 1949; 59: 694-704.

16. Jaklitsch MR, Decamp MM, Liptay MJ, et al. Videoassisted thoracic-surgery in the elderly - a review of 307 cases. Chest 1996; 110: 751-758.

17. Shah RM, Spirin PW, Salazar AM, Steiner RM, Cohn HE, Wechsler RJ. Role of thoracoscopy and preoperative localisation procedures in the diagnosis and management of pulmonary pathology. Semin Ultrasound CT MR 1995; 16: 371-378.

18. Landreneau RJ, Hazelrigg SR, Ferson PF. Thoracoscopic resection of 85 pulmonary lesions. Ann Thorac Surg 1992; 54: 415-420.

19. Ferson PF, Landreneau RJ, Dowling RD, et al. Comparison of open versus thoracoscopic lung-biopsy for diffuse infiltrative pulmonary-disease. $J$ Thorac Cardiovasc Surg 1993; 106: 194-199. 